\title{
PORTFOLIO VALUATION IN BANKS
}

\author{
David F. Hastings \\ Professor of the Accounting, Finance and Control Department \\ at FGV/EAESP and Executive Coordinator of the Center \\ for Excelence in Banking at FGV/EAESP. \\ E-mail: dhastings@fgvsp.br
}

\begin{abstract}
RESUMO
Encontram-se, com freqüência, referências ao uso de taxas de spread por carteira na gestão de riscos financeiros em bancos, mas são muito raras referências a procedimentos para determinar tais taxas. 0 propósito deste artigo é apresentar algumas idéias iniciais sobre 0 assunto: um sistema de Funding Padrão indica o quanto cada carteira deveria ter ganhado, enquanto um sistema de Funding Efetivo aponta o ganho efetivo de cada carteira; adicionalmente, a comparação entre os resultados dos dois sistemas de funding, para cada carteira, permite determinar 0 que cada carteira ganhou (ou perdeu) em termos de arbitragem.
\end{abstract}

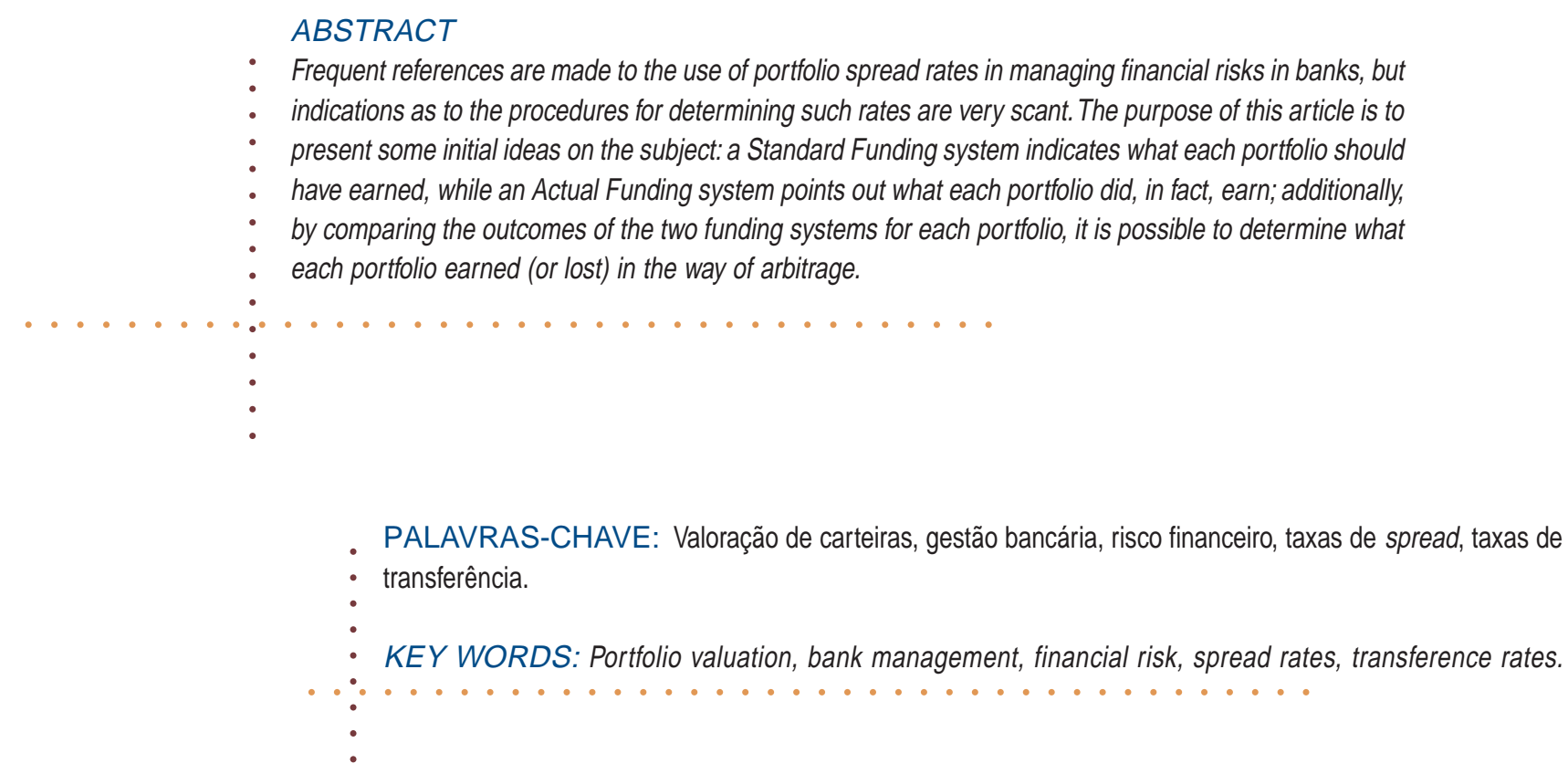




\section{INTRODUCTION - WHAT} ARE THE CHALLENGES?

The essence of any business undertaking is to run risks. Presumably, of course, whoever initiates the risky undertaking is better equipped than others to face the risks involved. It is precisely the ability to take on risks - and successfully overcome them - that ultimately adds value to any business undertaking.

When Mme. Channel launched a fashion collection for the upcoming season, or when Herr Porsche unveiled a new sports car, there was usually little surprise when the dresses or the cars turned out to be enormously successful because, in both cases, the experts were simply exercising their expertise: they knew what risks they were running, and they knew how to counter them. If, however, a collection of Porsche dresses or a new Channel car were to meet with any small degree of success, most everyone would probably be rather surprised. Obviously, Mme. Channel and Herr Porsche - both sound entrepreneurs - were well aware of their strengths and shortcomings and were careful not to overstep them.

The situation is no different in banking: bankers must be able to correctly assess the risks they are running and how such risks will (probably) evolve.

Banking, as with most other business undertakings, is subject to a wide range of risks, which act individually, and which interact collectively: among other categories, there are credit risks (borrowers may not repay what they owe), technology risks (the required procedures may change), sovereign risks (political scenarios may change) and, of course, financial risks.

To a certain extent, most categories of risks involved in banking are similar to comparable categories in other fields: retailers are subject to credit risks, manufacturers are subject to technology risks, everyone is subject to sovereign risks, and so forth. But the type of risk which sets banking apart from other activities, simply because it is related to the core business in banking, is the financial category of risks.

Very simply put, banks are engaged in leasing money - they lease money from other parties (by collecting deposits) and to other parties (by placing loans). The challenge which most typifies bank management has to do with assuring that the conditions negotiated in collecting deposits are in harmony with the conditions negotiated in placing loans.

Obviously, if a bank is to thrive, the interest it pays on deposits must be lower than the interest it charges on loans. But interest is a rather complex variable: it depends simultaneously on the rate, the maturity, and the regime, set for each transaction. In this context, I would outline these key variables as follows:

Rate: the percentage to be paid or charged on the principal over a given period of time: $15 \%$ a year, $1.2 \%$ a month, and so forth. It should be noted that rates are usually quoted (or at least reckoned) over and above a stipulated base rate: Libor $+15 \%$ a year, $1.2 \%$ a month over Prime, and such.

Maturity: the period of time to which each transaction refers - days, months, quarters, semesters, years, or any (sub)multiple of such periods.

Regime: the manner in which the base rate (and therefore, the overall rate) is acknowledged with regards to the maturity: present base rate (which amounts to a fixed overall rate) or future base rate (essentially, a variable overall rate). Portfolios which are free of interest (such as Demand Deposits, Floating Funds, Cash Reserves, and such) are labeled as neutral.

Ideally, in negotiating conditions, a bank would strive to ensure that maturities and regimes are exactly the same for deposits and loans and that rates are higher for loans than for deposits. If these conditions are met, then the bank's worries would be reduced to areas of risk other than the financial risk: officers would be able to concentrate on managing credit risks, technology risks, sovereign risks, ${ }^{1}$ etc. To a very large extent, management in banks would be comparable to management in any other field of activity.

Unfortunately, ideal conditions are rarely (if ever) attained. In conducting and maintaining hundreds, thousands, or even hundreds of thousands of transactions, however carefully rates are set, it would be virtually impossible for a bank to accurately balance out maturities and regimes for all its operations. And it should be noted that a single operation is enough to compromise the whole balancing act.

So, even assuming that rates are adequately matched, the occurrence of mismatches with regards to maturity and regime are practically inevitable. This, however, does not necessarily mean that banking operations will run at a loss - mismatches might, in fact, lead to larger earnings than would result from the ideally matched situation.

Let's assume, for instance, that a bank collects a certain amount of deposits at a 5\% fixed rate, for a given period, and that it places the same amount, for the same period, at a variable rate of $2 \%$ over the prime rate, which is at $4 \%$ at the time the transaction is agreed upon. If conditions remain stable, the bank would earn a spread of $1 \%$ at settlement. However, if the prime rate rises to $5 \%$, the spread at settlement would be $2 \%$. Obviously, if the prime rate sinks below $3 \%$, earnings would be negative. This is a case of regime mismatch. 
Alternately, we might assume that the bank collects a certain amount of deposits, again at a fixed rate of $5 \%$, for six months, and that it undertakes to place a loan of the same amount, at a fixed rate of $12 \%$, for one year. Clearly, the bank expects to renew its deposits, for a further six months, hopefully at the same rate. If everything turns out as expected, at the end of the year the bank will have earned a $2 \%$ spread. If, however, offered fixed rates for six-month deposits drop to $4 \%$, earnings will add up to $3 \%$ at the end of the year. If, on the other hand, offered fixed rates for deposits should rise, the bank may run into difficulties. This is a case of a maturity mismatch which may lead to a rate mismatch.

Using mismatches as a means of attempting to earn extra profits is one form of arbitraging.

Indications on how to deal effectively with mismatching risks - or "gaps" - are not difficult to come across ${ }^{2}$. Such indications, however, tend to focus on individual mismatching risks - rate, maturity, or regime gaps. The procedures suggested for dealing with these risks are usually elaborate, intelligent, constructive, and, moreover, sensible. But there is a further challenge, posed by the interaction of two or more gaps. And that is the challenge which I mean to address in this article.

\section{TRACKING THE ORIGINS OF EARNINGS - FUNDING SYSTEMS}

When a bank reckons its earnings, irrespective of whatever mismatches have occurred, the resulting figures merge earnings, stemming from the spread between the rates paid on deposits and those collected on loans, with the earnings (profits or losses), resulting from mismatches. My purpose, in this article, is to suggest means of separating the earnings, due to pure spreads, from those arising in arbitrage.

I usually employ the expression Funding System in describing the procedures employed to trace the flows of funds from "Sources" portfolios (deposits) to "Uses" portfolios (loans), or vice-versa, thereby ascertaining the financial earnings and the spread for each individual portfolio.

As an illustration, consider the overall "Monthly Statement of Financial Earnings" for an imaginary bank, presented in Exhibit 1, the contents of which are as follows:

Portfolio - the headers under which the bank collects sources of funds and places uses of funds.

Maturity - the time-span (in days) under which funds were originally collected or placed. Some peculiarities of this item should be clarified:
- In some cases, the reported Maturity is, to a certain extent, fictional. Demand Deposits, for instance, may be withdrawn from one day to the next - they have been reported at the shortest possible Maturity; Shareholders Equity, at the other extreme, is a permanent source of funds - it has been reported at the longest plausible Maturity; and Compulsory Reserves have been reported at a seven-day Maturity because they are adjusted weekly in Brazil, by the Central Bank.

- The fact that a certain amount has been reported under a certain maturity does not mean that the whole reported amount actually was present from the beginning to the end of the period considered. For instance, a certain amount may have been collected under 30-day maturity terms, but only on the $15^{\text {th }}$ of the month, in which case it would only be present in the second half of month.

Regime - as mentioned above, the manner in which the base rate is acknowledged with regards to the maturity.

Amount - figures represent the Mean Monthly Balance in each portfolio. If, for instance, $\$ 100$ is collected in deposits half-way through the month, it will be reckoned as $\$ 50$; if a loan of $\$ 100$ is redeemed on the $20^{\text {th }}$ day of the month, it will be reported as $\$ 66.67$. Positive figures represent sources of funds, while negative figures indicate uses of funds.

Inc./(Exp.) - interest income (positive figures) or expenditures (negative figures), on an accrual basis, for each portfolio. Expenditures on shareholders' equity represent dividends; income on fixed assets represents an increase in market value for the assets in question (the rate, in this case, may be estimated as the risk-free rate).

Rate - the percent rate of interest paid or charged within each portfolio.

The statement showed in Exhibit 1 tells us quite clearly exactly what Financial Earnings amounted to, in the period considered, for the whole bank, but it gives us absolutely no indication as to how much each portfolio contributed to overall earnings. In fact, as it stands, the statement has no way of breaking down overall earnings because, in order to do so, it first would have to break down the flows of funds to the individual portfolio level.

This is an old, and very common problem in banks - exactly how much did each portfolio earn?

One frequently found solution - based on a WACC approach - is to assume a transference rate equal to the Weighted Average Cost of Funds (WACF). The transference rate is simply the rate at which funds are "bought" and "sold" among portfolios within the bank. 
In the example under consideration, this rate would be $1.24 \%$. Thus, when funds are collected, they would automatically be sold at $1.24 \%$, and when funds are placed, they would automatically be bought at a cost of $1.24 \%$.

Under this approach, the earnings on each portfolio would be valued by the difference between its respective actual market rate and the transference rate. Thus: Demand Deposits $\Rightarrow(1.24 \%-0.00 \%)=1.24 \%$; Short TDs $\Rightarrow(1.24 \%-1.40 \%)=-0.16 \%$; Preferred Loans $\Rightarrow(1.82 \%-1.24 \%)=0.58 \%$; Personal Loans Var. $\Rightarrow(2.40 \%-1.24 \%)=1.16 \%$, and so on.

A direct variation to this approach would be to set the transference rate in accordance with the Weighted Average Yield of Funds (WAYF); $1.87 \%$ in our example. Under this variation, the same portfolios mentioned above would be valued as: Demand Deposits $\Rightarrow(1.87 \%-0.00 \%)=1.87 \%$; Short TDs $\Rightarrow(1.87 \%-$ $1.40 \%)=0.47 \%$; Preferred Loans $\Rightarrow(1.82 \%-1.87 \%)$ $=-0.05 \%$; Personal Loans - Var. $\Rightarrow(2.40 \%-1.87 \%)$ $=0.53 \%$, and so on.

An indirect variation of the above approaches uses a transference rate based on a market standard rate, such as the Interbank Rate, which tends to be situated somewhere between the WACF and the WAYF rates. For purposes of illustration, we might assume that the interbank rate, in our example, is $1.56 \%$. In this case, the aforementioned portfolios would be valued as:
Demand Deposits $\Rightarrow(1.56 \%-0.00 \%)=1.56 \%$; Short TDs $\Rightarrow(1.56 \%-1.40 \%)=0.16 \%$; Preferred Loans $\Rightarrow$ $(1.82 \%-1.56 \%)=0.26 \%$; Personal Loans - Var. $\Rightarrow$ $(2.40 \%-1.56 \%)=0.84 \%$, and so on.

These approaches are widely used for obvious reasons: they concentrate attention on the cheaper sources and on the more expensive uses of funds, and they are very easy to implement. However, they have one serious shortcoming: though their results will be at least roughly appropriate for the bank as a whole, they may not be true for the individual portfolios and their interplay.

Assuming that we employ the Market Standard Rate approach (which, in effect, represents an approach roughly midway between the WACF and the WAYF alternatives), let us consider, for example, the case of Demand Deposits: given the amount collected under this heading and a valuation rate of $1.56 \%$, this portfolio would be valued at $\$ 1,872(=\$ 120,000 \mathrm{x}$ $1.56 \%)$. Now, on another front, let's focus on Preferred Loans: in this case, the valuation rate is $0.26 \%$, meaning this portfolio will be valued at $\$ 46.80$.

The difficulty arises from the fact that there are definite (and, in some cases, mandatory) relationships between portfolios: a bank that collects Demand Deposits will have to maintain certain amounts in Cash Reserves, Compulsory Reserves, and (at least according to Brazilian rules) Preferred Loans.

Exhibit 1 - Bank XYZ - Monthly Statement of Financial Earnings

\begin{tabular}{|c|c|c|c|c|c|}
\hline Portfolio & Maturity & Regime & Amount & Inc./(Exp.) & Rate \\
\hline Sources of Funds & $-x-$ & $-x-$ & 696,000 & $(8,638.80)$ & $1.24 \%$ \\
\hline Demand Deposits & 1 & Neutral & 120,000 & 0.00 & $0.00 \%$ \\
\hline Short TDs - Fixed & 30 & Fixed & 240,000 & $(3,360.00)$ & $1.40 \%$ \\
\hline Medium TDs - Variable & 60 & Variable & 60,000 & $(888.00)$ & $1.48 \%$ \\
\hline Long TDs - Variable & 90 & Variable & 240,000 & $(3,768.00)$ & $1.57 \%$ \\
\hline Shareholders' Equity & 360 & Variable & 36,000 & $(622.80)$ & $1.73 \%$ \\
\hline Uses of Funds & $-x-$ & $-x-$ & $(696,000)$ & $13,014.12$ & $1.87 \%$ \\
\hline Cash Reserves & 1 & Neutral & $(4,800)$ & 0.00 & $0.00 \%$ \\
\hline Compulsory Reserves & 7 & Neutral & $(48,000)$ & 0.00 & $0.00 \%$ \\
\hline Preferred Loans & 180 & Variable & $(18,000)$ & 327.60 & $1.82 \%$ \\
\hline Commercial Loans - Fixed & 30 & Fixed & $(180,000)$ & $3,420.00$ & $1.90 \%$ \\
\hline Commercial Loans - Variable & 60 & Variable & $(276,000)$ & $5,713.20$ & $2.07 \%$ \\
\hline Personal Loans - Fixed & 30 & Fixed & $(44,400)$ & 990.12 & $2.23 \%$ \\
\hline Personal Loans - Variable & 90 & Variable & $(96,000)$ & $2,304.00$ & $2.40 \%$ \\
\hline Fixed Assets & 360 & Variable & $(28,800)$ & 259.20 & $0.90 \%$ \\
\hline Overall Financial Earnings & $-x-$ & $-x-$ & $-x-$ & $4,375.32$ & $0.63 \%$ \\
\hline
\end{tabular}


So let us now value the Demand Deposits portfolio linked to Cash Reserves, Compulsory Reserves, Preferred Loans, and assuming that whatever funds remain after these imposed linkages are placed in Variable Personal Loans (as this is the highest-rated Uses portfolio, it is obviously an optimistic assumption). The result of this exercise is as presented in Exhibit 2.

Comparing this result with what we had formerly obtained, it is immediately obvious that the Market Standard Rate procedure over-valued the Demand Deposit portfolio $(\$ 1,872.00>\$ 1,507.80)$. And we should keep in mind that, having adopted an optimistic assumption, the above result is, in itself, over-valued. ${ }^{3}$

We should also note that the Market Standard Rate procedure grossly under-valued the Preferred Loans portfolio which, reading between the lines of Exhibit 2 , should be valued at $\$ 327.00$, as opposed to the $\$ 46.80$ formerly indicated.

Now, if we can conduct this kind of analysis for all portfolios (both Sources and Uses), we will have succeeded in breaking down overall Financial Earnings into their individual portfolio components, which is what we originally set out to do. This is what we might label as an Actual Funding System.

\section{Actual Funding}

The only difficulty remaining, at this stage, is that some sort of rule must be set in order to define the sequential order in which portfolios will be drawn on (Sources), or filled in (Uses). Such a rule is needed so as to avoid the need of arbitrarily choosing the "next" portfolio, as we did in the example developed above when we chose the Variable Personal Loans portfolio as the destination for funds "left over" from the Demand Deposits portfolio.

For the purposes of assessing performance, "Sound Banking Practice" has long used the following general rule, known as the "Rate-Matching Rule": in dealing with multiple portfolios - Sources and Uses - subject to different rates, the cheaper Sources are used first, to fund the cheaper Uses; portfolios subject to higher rates are used only after the cheaper ones have been exhausted (Sources) or filled (Uses) (usually, one exception is adopted with regards to this rule: fixed assets are funded by equity. The reason for this exception is that these portfolios are the only ones to have an indefinite maturity - this is a case of "Maturity Matching").

If we accept this rule, building the funding system becomes a simple matter, somewhat similar to the "domino principle": start at the beginning, knock down all the pieces before you, one by one, till you come to the end; then stop. This may appear to be a rather deprecating way of referring to the matter, but, in fact, it is a fairly adequate way of describing the process.

Using a step-by-step approach, the process might be described as follows:

1. Identify the cheapest "Source" portfolio containing unused funds.

2. Channel such funds to the cheapest "Use" portfolio requiring funds, until the "Source" portfolio has been exhausted, or the "Use" portfolio has been completely filled in.

\section{3 . Return to 1.}

Having completed the part of the process dealing with sources (to uses), the uses (from sources) part is simply its "mirror image", as should become clear from the example given in Exhibit 3 (based on the figures contained in Exhibit 1).

The procedure described up to this point refers, of course, to the Amounts or "flows of funds"; once these have been determined, the income or expenditures for each item are calculated based on the rate originally given for the portfolio to which the item belongs.

Exhibit 2 - Bank XYZ - Earnings on Demand Deposits

\begin{tabular}{|c|c|c|c|}
\hline Portfolio & Amount & Inc./(Exp.) & Rate \\
\hline Source of Funds & 120,000 & 0.00 & $0.00 \%$ \\
\hline Demand Deposits & 120,000 & 0.00 & $0.00 \%$ \\
\hline Uses of Funds & $(120,000)$ & $1,507.80$ & $1.26 \%$ \\
\hline Cash Reserves & $(4,800)$ & 0.00 & $0.00 \%$ \\
\hline Compulsory Reserves & $(48,000)$ & 0.00 & $0.00 \%$ \\
\hline Preferred Loans & $(18,000)$ & 327.60 & $1.82 \%$ \\
\hline Personal Loans - Variable & $(49,200)$ & $1,180.80$ & $2.40 \%$ \\
\hline Overall Financial Earnings & $-x-$ & $1,507.80$ & $1.26 \%$ \\
\hline
\end{tabular}


The whole process may be rather troublesome - in the sense that it requires a lot of work - but conceptually it is really quite simple.

Thus, we have overcome the first part of our challenge; we now know exactly how much the bank actually earned in each of its portfolios and what the corresponding spread-rates were. But now we have to face the second part of the challenge - to ascertain what the bank gained or lost through arbitrage.

Exhibit 3 - A Funding System Report (Actual Approach)

\begin{tabular}{|c|c|c|c|}
\hline \multicolumn{4}{|c|}{ SOURCES } \\
\hline Portfolio & Amount & Inc./(Ехр.) & Rate \\
\hline $1^{\text {st }} S$ - Dem. Deposits & 120,000 & 0.00 & $0.00 \%$ \\
\hline $1^{\text {st }} \mathrm{U}$ - Cash Reserves & $(4,800)$ & 0.00 & $0.00 \%$ \\
\hline $2^{\text {nd }} U$ - Comp. Reserves & $(48,000)$ & 0.00 & $0.00 \%$ \\
\hline $3^{\text {rd }} \mathrm{U}$ - Pref. Loans & $(18,000)$ & 327.60 & $1.82 \%$ \\
\hline $4^{\text {th }} \mathrm{U}-$ Com. Loans - F & $(49,200)$ & 934.80 & $1.90 \%$ \\
\hline Financial Earnings & & $1,262.40$ & $1.05 \%$ \\
\hline $2^{\text {nd }} S$ - Short TDs - F & 240,000 & $(3,360.00)$ & $1.40 \%$ \\
\hline $1^{\text {st }} \mathrm{U}$ - Com. Loans - F & $(130,800)$ & $2,485.20$ & $1.90 \%$ \\
\hline $2^{\text {nd }} U$ - Com. Loans - V & $(109,200)$ & $2,260.44$ & $2.07 \%$ \\
\hline Financial Earnings & & 1.385 .64 & $0.58 \%$ \\
\hline $3^{\text {rd }}$ S - Medium TDs - V & 60,000 & $(888.00)$ & $1.48 \%$ \\
\hline $1^{\text {st }} \mathrm{U}$ - Com. Loans - V & $(60,000)$ & $1,242.00$ & $2.07 \%$ \\
\hline Financial Earnings & & 354.00 & $0.59 \%$ \\
\hline $4^{\text {th }} S$ - Long TDs - V & 240,000 & $(3,768.00)$ & $1.57 \%$ \\
\hline $1^{\text {st }} \mathrm{U}$ - Com. Loans - V & $(106,800)$ & $2,210.76$ & $2.07 \%$ \\
\hline $2^{\text {nd }} \mathrm{U}$ - Pers. Loans - F & $(44,400)$ & 990.12 & $2.23 \%$ \\
\hline $3^{\text {rd }}$ U - Pers. Loans - V & $(88,800)$ & $2,131.20$ & $2.40 \%$ \\
\hline Financial Earnings & & $1,564.08$ & $0.66 \%$ \\
\hline $5^{\text {th }} S$ - Equity & 36,000 & $(622.80)$ & $1.73 \%$ \\
\hline $1^{\text {st }} U$ - Pers. Loans - V & $(7,200)$ & 172.80 & $2.40 \%$ \\
\hline $2^{\text {nd }} U$ - Fixed Assets & $(28,800)$ & 259.20 & $0.90 \%$ \\
\hline Financial Earnings & & $(190.80)$ & $-0.53 \%$ \\
\hline Overall Financial Earnings & & $4,375.32$ & $0.63 \%$ \\
\hline
\end{tabular}

As mentioned before, Arbitrage involves the use of mismatches in the hopes of earning extra profits. In other words, the use of arbitrage implies that the rules of maturity and regime matching have not been followed. But that is exactly the way we built the Actual Funding System - we followed the Rate Matching Rule, but disregarded the rules dealing with maturity and regime. Consequently, the results presented in the funding system we have already built contain the earnings derived from arbitraging,

\begin{tabular}{|c|c|c|c|}
\hline \multicolumn{4}{|c|}{ USES } \\
\hline Portfolio & Amount & Inc./(Exp.) & Rate \\
\hline $1^{\text {st }} \mathrm{U}$ - Cash Reserves & $(4,800)$ & 0.00 & $0.00 \%$ \\
\hline $1^{\text {st }} S$ - Dem. Deposits & 4,800 & 0.00 & $0.00 \%$ \\
\hline Financial Earnings & & 0.00 & $0.00 \%$ \\
\hline $2^{\text {nd }} \mathrm{U}$ - Comp. Reserves & $(48,000)$ & 0.00 & $0.00 \%$ \\
\hline $1^{\text {st }} S$ - Dem. Deposits & 48,000 & 0.00 & $0.00 \%$ \\
\hline Financial Earnings & & 0.00 & $0.00 \%$ \\
\hline $3^{\text {rd }} \mathrm{U}$ - Pref. Loans & $(18,000)$ & 327.60 & $1.82 \%$ \\
\hline $1^{\text {st }} S$ - Dem. Deposits & 18,000 & 0.00 & $0.00 \%$ \\
\hline Financial Earnings & & 327.60 & $1.82 \%$ \\
\hline $4^{\text {th }} \mathrm{U}-$ Com. Loans - F & $(180,000)$ & $3,420.00$ & $1.90 \%$ \\
\hline $1^{\text {st }} S$ - Dem. Deposits & 49,200 & 0.00 & $0.00 \%$ \\
\hline $2^{\text {nd }} S$ - Short TDs - F & 130,800 & $(1,831.20)$ & $1.40 \%$ \\
\hline Financial Earnings & & $1,588.80$ & $0.88 \%$ \\
\hline $5^{\text {th }} \mathrm{U}-$ Com. Loans - V & $(276,000)$ & $5,713.20$ & $2.07 \%$ \\
\hline $1^{\text {st }} \mathrm{S}$ - Short TDs - F & 109,200 & $(1,528.80)$ & $1.40 \%$ \\
\hline $2^{\text {nd }} S$ - Medium TDs - V & 60,000 & $(888.00)$ & $1.48 \%$ \\
\hline $3^{\text {rd }} S$ - Long TDs - V & 106,800 & $(1,676.76)$ & $1.57 \%$ \\
\hline Financial Earnings & & $1,619.64$ & $0.59 \%$ \\
\hline $6^{\text {th }} \mathrm{U}$ - Pers. Loans - F & $(44,400)$ & 990.12 & $2.23 \%$ \\
\hline $1^{\text {st }} \mathrm{S}$ - Long TDs - V & 44,400 & (697.08) & $1.57 \%$ \\
\hline Financial Earnings & & 293.04 & $0.66 \%$ \\
\hline $7^{\text {th }} \mathrm{U}$ - Pers. Loans - V & $(96,000)$ & $2,304.00$ & $2.40 \%$ \\
\hline $1^{\text {st }} \mathrm{S}$ - Long TDs - V & 88,800 & $(1,394.16)$ & $1.57 \%$ \\
\hline $2^{\text {nd }} S$ - Equity & 7,200 & (124.56) & $1.73 \%$ \\
\hline Financial Earnings & & 785.28 & $0.82 \%$ \\
\hline $8^{\text {th }} U$ - Fixed Assets & $(28,800)$ & 259.20 & $0.90 \%$ \\
\hline $1^{\text {st }} S$ - Equity & 28,800 & $(498.24)$ & $1.73 \%$ \\
\hline Financial Earnings & & $(239.04)$ & $-0.83 \%$ \\
\hline Overall Financial Earnings & & $4,375.32$ & $0.63 \%$ \\
\hline
\end{tabular}


together with those produced by simple financial intermediation.

Therefore, if we can now build another funding system, which follows all three matching-rules, we could then compare results obtained in both funding systems in such a way as to separate arbitrage earnings from the rest.

We might label this new approach a Standard Funding System. Standard because it would indicate what the bank should have earned on each portfolio, if it had carefully followed all matching rules.

\section{Standard Funding}

As might be expected, in order to build our Standard Funding System, we will rely on a set of definitions derived from the matching rules we intend to employ. Such definitions are as follows:

- Every "Source" of funds shall be fully channeled to "Uses" under the same maturity, and every "Use" of funds shall be fully supplied by "Sources" under the same maturity.

- Every "Source" of funds shall be fully channeled to "Uses" under the same regime, and every "Use" of funds shall be fully supplied by "Sources" under the same regime.

- Surplus "Neutral" funds shall be channeled in accordance with the Rate Matching Rule.

- If any "Source" has two or more possible "Uses" under the same maturity and regime, the cheaper "Uses" shall be used first, and if any "Use" has two or more possible "Sources" under the same maturity and regime, the cheaper "Sources" shall be used first.

- Mandatory "Source-Use" relationships shall be followed.
Considering the portfolios that we are dealing with, the above definitions would lead to the "matches" showed in Exhibit 4.

In most cases, the relationships - and their results - will not be surprising in any way, but there are two special, but reasonably common, situations which merit discussion.

- What happens if there is not enough of a given source to fill in a set of uses, or vice-versa?

According to the first rule above, we would have to expand uses so as to fully absorb their sources, or expand sources so as to complete their uses. If we should need to expand sources (in order to complete filling in uses), the expansion should be on the last portfolio used; if the expansion is of uses (in order to complete the placement of sources), then it should be on the first portfolio used (within each category of "Source-Use" relationships, of course).

- What happens if there are no uses for a given source, or vice-versa?

We would then have to "invent" a portfolio by interpolating or extrapolating the rates on the nearest comparable existent portfolios. Supposing, for instance, that there were a 120-day variable portfolio on the "Uses" side, we would have to introduce an "imaginary" "Source" portfolio subject to the same conditions. We would then have to extrapolate the rates of the 60 and 90-day variable "Source" portfolios, which would give us a rate of approximately $1.66 \%$ (in this illustration, I have used a very simple linear extrapolation, which might not be valid in more complex situations - the method to be employed in such estimates is a matter of choice and judgement in each particular instance).

So, having our definitions, we can now build our Standard Funding System, as presented in Exhibit 5.

Exhibit 4 - Standard Source-Use Relationships

\begin{tabular}{|c|c|c|c|c|c|c|c|}
\hline \multicolumn{4}{|c|}{ SOURCES } & \multicolumn{4}{|c|}{ USES } \\
\hline Portfolio & Maturity & Regime & Rate & Portfolio & Maturity & Regime & Rate \\
\hline Demand Deposits & 1 & Neutral & $0.00 \%$ & $\begin{array}{l}\text { Cash Reserves } \\
\text { Compulsory Reserves } \\
\text { Preferred Loans* }\end{array}$ & $\begin{array}{r}1 \\
7 \\
180\end{array}$ & $\begin{array}{l}\text { Neutral } \\
\text { Neutral } \\
\text { Variable }\end{array}$ & $\begin{array}{l}0.00 \% \\
0.00 \% \\
1.82 \%\end{array}$ \\
\hline Short TDs - Fixed & 30 & Fixed & $1.40 \%$ & $\begin{array}{l}\text { Commercial Loans - Fixed } \\
\text { Personal Loans - Fixed }\end{array}$ & $\begin{array}{l}30 \\
30\end{array}$ & $\begin{array}{l}\text { Fixed } \\
\text { Fixed }\end{array}$ & $\begin{array}{l}1.90 \% \\
2.23 \%\end{array}$ \\
\hline Medium TDs - Variable & 60 & Variable & $1.48 \%$ & Commercial Loans - Variable & 60 & Variable & $2.07 \%$ \\
\hline Long TDs - Variable & 90 & Variable & $1.57 \%$ & Personal Loans - Variable & 90 & Variable & $2.40 \%$ \\
\hline Shareholders' Equity & 360 & Variable & $1.73 \%$ & Fixed Assets & 360 & Variable & $0.90 \%$ \\
\hline
\end{tabular}

*According to Brazilian Banking Regulations, Preferred Loans are mandatory if a bank collects Demand Deposits. 
And so, we have overcome the second part of our challenge; we now know exactly how much the bank should have earned in each of its portfolios and what the corresponding spread-rates would have been, if it had carefully followed the matching rules. But now we have to face the third and last part of the challenge - to separate gains or losses through arbitrage from the bank's overall earnings.

It should be stressed that all figures for earnings, in the aforementioned tabulation, exist only in theory they represent what should have happened. Furthermore, as Expansions may not be the same in the "Sources" and the "Uses" viewpoints, the sum-total for earnings tends to differ from one to the other.

Exhibit 5 - A Funding System Report (Standard Approach)

\begin{tabular}{|c|c|c|c|c|c|c|c|}
\hline \multicolumn{4}{|c|}{ SOURCES } & \multicolumn{4}{|c|}{ USES } \\
\hline Portfolio & Amount & Inc./(Exp.) & Rate & Portfolio & Amount & Inc./(Exp.) & Rate \\
\hline $1^{\text {st }} S$ - Dem. Deposits & 120,000 & 0.00 & $0.00 \%$ & $1^{\text {st }} \mathrm{U}$ - Cash Reserves & $(4,800)$ & 0.00 & $0.00 \%$ \\
\hline $1^{\text {st }} \mathrm{U}$ - Cash Reserves & $(4,800)$ & 0.00 & $0.00 \%$ & $1^{\text {st }} S$ - Dem. Deposits & 4,800 & 0.00 & $0.00 \%$ \\
\hline $2^{\text {nd }} U$ - Comp. Reserves & $(48,000)$ & 0.00 & $0.00 \%$ & Financial Earnings & & 0.00 & $0.00 \%$ \\
\hline $3^{\text {rd }} \mathrm{U}$ - Pref Loans & $(100001$ & 200 & 1000 & $2^{\text {nd }} \mathrm{U}$ - Comp. Reserves & $(48,000)$ & 0.00 & $0.00 \%$ \\
\hline & & & & $1^{\text {st }} S$ - Dem. Deposits & 48,000 & 0.00 & $0.00 \%$ \\
\hline $4^{\text {th }} \mathrm{U}-$ Com. Loans - F & $(49,200)$ & 934.80 & $1.90 \%$ & Financial Earnings & & 0.00 & $0.00 \%$ \\
\hline Financial Earnings & & $1,262.40$ & $1.05 \%$ & $3^{\text {rd }} \mathrm{U}$ - Pref. Loans & $(18,000)$ & 327.60 & $1.82 \%$ \\
\hline $2^{\text {nd }} S$ - Short TDs - F & 240,000 & $(3,360.00)$ & $1.40 \%$ & $1^{\text {st }} S$ - Dem. Deposits & 18,000 & 0.00 & $0.00 \%$ \\
\hline $1^{\text {st }} \mathrm{U}$ - Com. Loans - F & $(180,000)$ & $3,420.00$ & $1.90 \%$ & Financial Earnings & & 327.60 & $1.82 \%$ \\
\hline $2^{\text {nd }} \mathrm{U}$ - Pers. Loans - F & $(44,400)$ & 990.12 & $2.23 \%$ & $4^{\text {th }} \mathrm{U}-$ Com. Loans - F & $(180,000)$ & $3,420.00$ & $1.90 \%$ \\
\hline Expanded Use & $(15,600)$ & 296.40 & $1.90 \%$ & $1^{\text {st }} \mathrm{S}$ - Short TDs - F & 180,000 & $(2,520.00)$ & $1.40 \%$ \\
\hline Financial Earnings & & $1,346.52$ & $0.56 \%$ & Financial Earnings & & 900.00 & $0.50 \%$ \\
\hline ard C M M & 00000 & 1000001 & $1,100 /$ & $5^{\text {th }} \mathrm{U}-$ Com. Loans - V & $(276,000)$ & $5,713.20$ & $2.07 \%$ \\
\hline 3 - IVIedium IDs - & 60,000 & (888.00) & $1.48 \%$ & $1^{\text {st }} S$ - Medium TDs - V & 60,000 & $(888.00)$ & $1.48 \%$ \\
\hline $1^{\text {st }} \mathrm{U}$ - Com. Loans - V & $(60,000)$ & $1,242.00$ & $2.07 \%$ & Expanded Source & 216,000 & $(3,196.80)$ & $1.48 \%$ \\
\hline Financial Earnings & & 354.00 & $0.59 \%$ & Financial Earnings & & $1,628.40$ & $0.59 \%$ \\
\hline $4^{\text {th }} \mathrm{S}$ - Long TDs - V & 240,000 & $(3,768.00)$ & $1.57 \%$ & $6^{\text {th }}$ U - Pers. Loans - F & $(44,400)$ & 990.12 & $2.23 \%$ \\
\hline $1^{\text {st }} \mathrm{U}$ - Pers. Loans - V & $(96,000)$ & $2,304.00$ & $2.40 \%$ & $1^{\text {st }} S$ - Short TDs - F & 44,400 & $(621.60)$ & $1.40 \%$ \\
\hline Expanded Use & $(144,000)$ & $3,456.00$ & $2.40 \%$ & Financial Earnings & & 368.52 & $0.83 \%$ \\
\hline Financial Earnings & & $1,992.00$ & $0.83 \%$ & $7^{\text {th }} \mathrm{U}$ - Pers. Loans - V & $(96,000)$ & $2,304.00$ & $2.40 \%$ \\
\hline $5^{\text {th }} S-$ Equity & 36.000 & $(622.80)$ & $173 \%$ & $1^{\text {st }} \mathrm{S}$ - Long TDs - V & 96,000 & $(1,507.20)$ & $1.57 \%$ \\
\hline 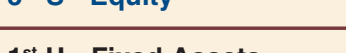 & & & & Financial Earnings & & 796.80 & $0.83 \%$ \\
\hline $1^{\text {st }}$ U - Fixed Assets & $(28,800)$ & 259.20 & $0.90 \%$ & $8^{\text {th }} \mathrm{U}$ - Fixed Assets & $(28,800)$ & 259.20 & $0.90 \%$ \\
\hline Expanded Use & $(7,200)$ & 64.80 & $0.90 \%$ & $1^{\text {st }} S$ - Equity & 28,800 & (498.24) & $1.73 \%$ \\
\hline Financial Earnings & & $(298.80)$ & $-0.83 \%$ & Financial Earnings & & $(239.04)$ & $-0.83 \%$ \\
\hline Overall Financial Earnings & & $4,656.12$ & $0.67 \%$ & Overall Financial Earnings & & $3,781.38$ & $0.54 \%$ \\
\hline
\end{tabular}

\section{Actual Vs. Standard Funding $\Rightarrow$ Arbitrage Earnings}

Having gone through all this work, the last phase of our challenge is really quite easy: all we have to do is to compare portfolio earnings under the two funding approaches.

As the Actual Funding System indicates total earnings for each portfolio, while the Standard Funding System points out the strictly financial earnings (assuming that maturities and regimes have been adequately matched), the difference from one to the other funding approach will indicate arbitrage earnings (which may be positive or negative) for each portfolio. 
The procedure is perfectly straightforward: for each portfolio, we simply subtract the earnings, indicated in the Standard Funding report, from the corresponding earnings indicated in the Actual Funding report, as shown in Exhibit 6.

Having generated this information, we should now analyze it with a view to determine which portfolios have compromised performance, and which have enhanced it. If possible, it would also be advisable to attempt to identify the reasons which led to arbitrage gains or losses, and how such reasons might threaten the bank's future performance. Such an analysis might present itself as follows:

- Demand Deposits: although this portfolio is neutral, as regards rates, it is highly volatile in terms of maturity (in the sense that the amount may vary - up or down - from one moment to the next). This situation would be risky if the amount collected under this heading should drop. As, in part, it is being channeled to portfolios with longer maturities (which, by definition, indicates arbitrage), a drop in Demand Deposits might cause arbitrage gains or losses in other portfolios (Preferred Loans and 30day Commercial Loans, in the example given). In other words, this is a portfolio which is naturally prone to arbitrage risks (even if indirectly), and, therefore, deserves to be monitored carefully. In the example developed above, arbitrage earnings are not directly manifest because we analyzed the portfolio, from two different viewpoints, for a single period of time.

- Short Time Deposits: the arbitrage gain of $\$ 39.12$ is due to the fact that, though Standard funding would direct a part of the amount to a higher rated "Use" portfolio (2.23\% Vs. 2.07\%), a higher proportion of the amount goes to a better rate in Actual funding; the shift in proportions outweighs the shift in rates, favouring the Actual situation.

- Medium Time Deposits: in this instance, there is no gain or loss in arbitrage simply because the "Source" and the "Use" portfolios are, in fact, perfectly matched. This, however, may be lucky coincidence.

- Long Time Deposits: the arbitrage loss of $\$ 427.92$ stems from the fact that, in Actual funding, roughly $2 / 3$ of the amount collected in this portfolio were channeled to "Uses" subject to rates lower than what Standard funding would stipulate. From the financial point of view, it would be advisable for the bank to increase its 90-day Personal Loans Portfolio (possibly decreasing its 60-day Commercial Loans and 30-day Personal Loans portfolios).

- Shareholders' Equity: from a purely financial point of view, equity is a necessary evil - by definition it is the most expensive "Source" of funds (under normal conditions), but it is required by government regulation. Even so, it earned an arbitrage gain of $\$ 108.00$ because, from the

Exhibit 6 - Arbitrage Gains and Losses

\begin{tabular}{|c|c|c|c|c|c|}
\hline Portfolio & Maturity & Regime & $\begin{array}{l}\text { Actual } \\
\text { Earnings } \\
\text { (A) }\end{array}$ & $\begin{array}{l}\text { Standard } \\
\text { Earnings } \\
\text { (B) }\end{array}$ & $\begin{array}{l}\text { Arbitrage } \\
\text { Earnings } \\
C=(A-B)\end{array}$ \\
\hline Demand Deposits & 1 & Neutral & $1,262.40$ & $1,262.40$ & 0.00 \\
\hline Short Time Deposits - F & 30 & Fixed & $1,385.64$ & $1,346.52$ & 39.12 \\
\hline Medium Time Deposits - V & 60 & Variable & 354.00 & 354.00 & 0.00 \\
\hline Long Time Deposits - V & 90 & Variable & $1,564.08$ & $1,992.00$ & (427.92) \\
\hline Shareholders' Equity & 360 & Variable & $(190.80)$ & $(298.80)$ & 108.00 \\
\hline Cash Reserves & 1 & Neutral & 0.00 & 0.00 & 0.00 \\
\hline Compulsory Reserves & 7 & Neutral & 0.00 & 0.00 & 0.00 \\
\hline Preferred Loans & 180 & Variable & 327.60 & 326.70 & 0.00 \\
\hline Commercial Loans - F & 30 & Fixed & $1,588.80$ & 900.00 & 688.80 \\
\hline Commercial Loans - V & 60 & Variable & $1,619.64$ & $1,628.40$ & (8.76) \\
\hline Personal Loans - F & 30 & Fixed & 293.04 & 368.52 & (75.48) \\
\hline Personal Loans - V & 90 & Variable & 785.28 & 796.80 & (11.52) \\
\hline Fixed Assets & 360 & Variable & (239.04) & (239.04) & 0.00 \\
\hline \multicolumn{5}{|l|}{ Total Arbitrage Earnings } & 312.24 \\
\hline
\end{tabular}


Standard viewpoint the whole amount should be channeled to Fixed Assets, whereas in the Actual approach it has been channeled in part to Personal Loans, at a higher rate.

- Cash Reserves: a bank only holds Cash Reserves if it has collected Demand Deposits, so the one will always be funded by the other. I can't think of any situation under which Cash Reserves might generate arbitrage earnings.

- Compulsory Reserves: again, a bank only maintains Compulsory Reserves if it has collected Demand Deposits. However, as Compulsory Reserves are adjusted a certain period of time after the Demand Deposits have been held, mismatches may appear, and, at least in theory, could cause arbitrage losses. On the other hand, there really is not much that can be done to remedy this situation.

- Preferred Loans: as this portfolio has been "forcefully" matched with Demand Deposits, it is not very surprising that arbitrage earnings did not surface. However, it should be noted that, as Preferred Loans are a rather long-term portfolio, whereas Demand Deposits constitute an extremely short-term portfolio, mismatches can (and do!) occur (this is the other side of the comment regarding the Demand Deposits portfolio, above).

- Commercial Loans - F: the rather large arbitrage gain $-\$ 688.80$ - is due to the fact that, according to Standard funding, this portfolio should be entirely funded by Short TDs - F whereas, in actual fact, it was partially funded by Demand Deposits. As this is one of the cheaper "Use" portfolios, it will usually benefit from very cheap "Sources", so this result is not surprising (but once again, the comment regarding Demand Deposits, as presented above, may come to bear on this portfolio).

- Commercial Loans - V: the apparently negligible arbitrage loss - (\$8.76) - indicated for this portfolio is, in fact, the result of larger variations which almost cancel out. In theory, this "Use" portfolio should be supplied entirely by Medium TDs - V, at a cost of $1.48 \%$. In fact, only about $22 \%$ of the funds were supplied at the expected rate; approximately 39\% came from Short TDs - V, at $1.40 \%$, and roughly another 39\% came from Long TDs - F, at $1.57 \%$. It should be noted that mismatches in maturity always subject end-results to uncertainty, sometimes with a positive outcome, but sometimes with unwelcome surprises. To a large extent, whether the outcome is positive or negative depends on the tendencies surrounding interest rates. In this case, as the loans are on a variable basis, if there is an upward tendency in the rates, funding based on fixed rate "Sources" will enhance earnings, but if rates are sliding, fixed rate Sources might be disastrous. Obviously, if the regimes were adequately matched, the bank would be in a relatively safe position, but would probably not be expecting outstanding results.

- Personal Loans - F: the arbitrage loss of (\$75.48) incurred in this portfolio stems from the fact that, whereas it should have been funded by Short TDs $-\mathrm{F}$, at $1.40 \%$, it was in fact funded by Long TDs $\mathrm{V}$, at $1.57 \%$ (because Short TDs - F had already been allocated to other "Uses"). Note that, in this case, we have a double mismatch, both in maturity and in regime. This might be quite dangerous.

- Personal Loans - V: in this case, the arbitrage loss of (\$11.52) was caused by a shortage of the appropriate "Source" (Long TDs -V, at 1.57\%), which had already been consumed by other "Uses", so that a more expensive "Source" had to be used the effect was relatively insignificant because the mismatch was not very large.

- Fixed Assets: As the match with equity is habitually "forced" on this "Use" portfolio, it rarely produces arbitrage earnings - neither gains nor losses.

Hopefully, with the information generated in our funding systems and based on the analyses we can conduct on such information, we will be better qualified to meet our bank management challenges, at least in the sphere of financial risks.
1. Or, in other words, valuation in banks would be the same as in any other area, and the $\beta$ factor (as in CAPM, for instance) would indicate the difference in rates, from deposits to loans, needed to offset such risks and generate profit.
2. KOCH, Timothy W. Bank management, Dryden, 1995 , SAUNDERS, Anthony. Financial institutions management a modern perspective. Irwin, 1997, and SINKEY JR., Joseph F. Commercial bank financial management. MacMillan, 1992, are outstanding examples of such references.
3. I must admit that, in using Demand Deposits as an illustration, I deliberately chose to "play with marked cards". Despite this undeniable fact, I am confident that the illustration points out the equally undeniable fact that the WACF, WAYF, and Market Standard Rate procedures are subject to serious distortions. 